American Journal of Infectious Diseases 5 (4): 273-281, 2009

ISSN 1553-6203

(C) 2009 Science Publications

\title{
The Health and Toxic Adverse Effects of Fusarium Fungal Mycotoxin, Fumonisins, on Human Population
}

\author{
${ }^{1,2}$ W.M. Wan Norhasima, ${ }^{3}$ A.S. Abdulamir, ${ }^{1}$ F. Abu Bakar, ${ }^{1}$ R. Son and ${ }^{2}$ A. Norhafniza \\ ${ }^{1}$ Faculty of Food Science and Technology, \\ University Putra Malaysia, 43400 Serdang, Selangor, Malaysia \\ ${ }^{2}$ Biotechnology Research Centre, \\ Malaysian Agricultural Research and Development Institute Headquarters, \\ P.O. Box 12301, GPO 50774, Kuala Lumpur, Malaysia \\ ${ }^{3}$ Institute of Bioscience, University Putra Malaysia, 43400 Serdang, Selangor, Malaysia
}

\begin{abstract}
Problem statements: Fumonisin was a mycotoxin produced mainly by fungi belonging to the genus Fusarium in various foods and feeds. They occurred worldwide and were found predominantly in corn and in corn-based animal feeds and also can be found in other crops. Contamination of food and feed with fumonisins has been implicated in and associated with a number of diseases in both livestock as well as human beings. Approach: A review was done on the effect of fumonisins on animal and human and detoxification method for the prevention. ScienceDirect, Scopus, PubMed, Google and Yahoo were used in the preparation of this review. Results: This review clarified that the major forms of fumonisins found in food were the B series, fumonisin B1, B2 and B3. Fumonisin B1 (FB1) was the most common and the most thoroughly studied. FB1 caused toxicities in animals including Equine Leukoencephalomalacia (ELEM), Porcine Pulmonary Edema (PPE) in pigs and nephrotoxic, hepatotoxic and hepatocarcinogenic in rats. Furthermore, FB1 had been implicated to be associated with high rates of human esophageal cancer. In addition to their natural occurrence in corn-based animal feeds and in home-grown corn used for food, fumonisins were frequently found in commercial corn-based foods. Methods for prevention and detoxification for fumonisins included prevention of plants contamination at the field level and harvest and post-harvest control of fumonisins. Furthermore, the diseases occurred in livestock will pose the additional economic losses in livestock farmers. Conclusion: Due to economic losses engendered by fumonisin, several strategies for detoxifying and preventing contaminated foods and feeds had been described in the literature including physical and biological process. However these methods still in demonstrated. Awareness of fumonisin-related animal diseases, contamination of fumonisin in foods and feeds and adherence to guidance recommendation in prevention methods were important for reducing fumonisin-induced diseases in agriculturally important species.
\end{abstract}

Key words: Fumonisin B1, leukoencephalomalacia, pulmonary edema, toxicity

\section{INTRODUCTION}

Fumonisins are mycotoxins produced by a variety of fungi of the Fusarium genus, Fusarium verticillioides (formally F. moniliforme; telemorph Gibberella fujikuroi), $F$. proliferatum and other Fusarium species $^{[1]}$. Fumonisins were first isolated in 1988 by Gelderblom and colleagues from cultures of $F$. verticillioides strain MRC $826^{[1]}$.

Fumonisins are natural contaminants of cereal grains worldwide and are mostly found in corn and products derived from $\operatorname{corn}^{[2]}$. There is also evidence that fumonisin occur in other crops such as sorghum ${ }^{[3]}$, white beans, adzuki beans, mung beans ${ }^{[4]}$, wheat, barley, soybean, black tea and medicinal plants ${ }^{[5]}$. Fumonisins are important naturally-occuring mycotoxins and the most abundant species in nature is Fumonisin B1 (FB1), followed by Fumonisin B2 (FB2) and Fumonisin B3 (FB3).

Experts at the Food and Agriculture Organization (FAO) of the United Nations have estimated that over $25 \%$ of the world's food crops are lost each year due to mycotoxin contamination, with the Fusarium species contributing substantially to food contamination ${ }^{[6]}$.

Corresponding Author: F. Abu Bakar, Faculty of Food Science and Technology, University Putra Malaysia, 43400 Serdang, Selangor, Malaysia 
Several species of Fusarium that are important field or pre-harvest pathogens, namely, $F$. graminearum, $F$. culmorum, $F$. verticillioides and $F$. proliferatum cause substantial crop damage due to root, stalk and ear $\operatorname{rot}^{[7]}$. In addition to the structural damage to crops, these Fusarium species are capable of producing a variety of fungal toxins, such as zearalenone, zearalenols, trichothecenes, fumonisins, fusarins and moniliformin which threaten the health of humans and animals that consume them.

The most investigated fumonisin is FB1, which can cause severe disorders in animals such as Equine Leukoencephalomalacia (ELEM) ${ }^{[8]}$, pulmonary edema syndrome and hydrothorax in pigs ${ }^{[9]}$ and it is nephrotoxic, hepatotoxic and hepatocarcinogenic in rats. Furthermore, FB1 has been implicated to be associated with high rates of human esophageal cancer in South Africa, the United States and China ${ }^{[10]}$.

The current review outlines the role of fumonisin as food toxin. More over it shed light on the Fusarium species that produce fumonisin B1 namely, Fusarium verticillioides and Fusarium proliferatum. The goal of the current review is to address the properties of the fumonisin contaminated foods and feeds especially corn and corn-based products and toxicological effect that cause diseases in horse and pigs that give impact in economy. Furthermore, the health impact of fumonisin on human is highlighted too. The other purpose is to explore the potential methods that can be used in detoxification fumonisins.

Chemical and physical properties of fumonisins: Fumonisins are family of more than ten mycotoxins produced by Fusarium verticillioides and related species in corn worldwide. They are polar compounds and soluble in water and aqueous solutions such as methanol and acetonitrile, but they are not soluble in non-polar solvents. The physical or chemical properties of the fumonisins can have been clarified by some previous reports ${ }^{[11,12]}$.

Fumonisins do not have a cyclic structure which is found in most mycotoxins. They are characterized by a 19- or 20-carbon aminopolyhydroxyalkyl chain that is diesterified with propane-1, 2, 3-tricarboxylic acid groups (tricarballylic acid) ${ }^{[13]}$ (Fig. 1 and Table 1).

Fumonisins that have been isolated from cultures of $F$. verticillioides and/or corn-based food are chemically related groups or series (A, B, C and P). Among the forms that have been characterized, are Fumonisin B1 (FB1), Fumonisin B2 (FB2) and fumon.isin B3 (FB3) (the B series of fumonisins) ${ }^{[14,17]}$.

Fumonisin B1 is also known as macrofusin and the most abundant of the fumonisin family and usually accounts for $70-80 \%$ of the total fumonisin content of $F$. verticillioides cultures and naturally contaminated foods $^{[18]}$ (Fig. 2). Fumonisins B2 and B3 usually make up $15-25$ and $3-8 \%$, respectively, of the fumonisin content of food.
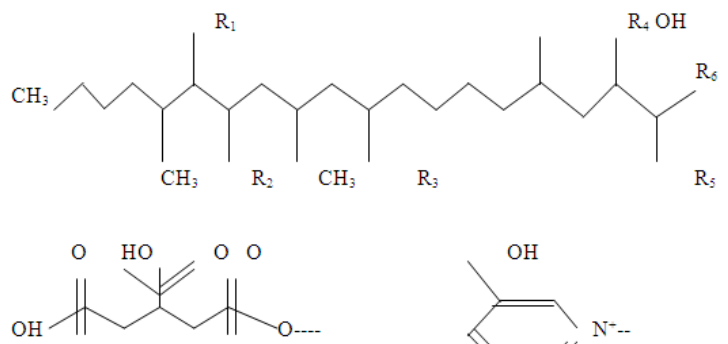

Tricarballylic Acid (TCA)

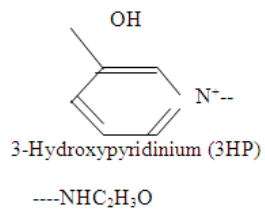

N-Carboxymethyl (NCM)

N-Acetyl (NAC)

$---\mathrm{NH}\left(\mathrm{C}_{6} \mathrm{H}_{11} \mathrm{O}_{5}\right)$

N-1-Deoxy-D-fructose-1-y1 (NDF)

Fig. 1: Chemical structures of the fumonisin ${ }^{[14-16]}$

Table 1 Chemical structures and molecular weight of the fumonisins.

\begin{tabular}{|c|c|c|c|c|c|c|c|c|c|}
\hline \multirow[b]{2}{*}{ Fumonisin } & \multicolumn{6}{|c|}{ Group } & \multirow[b]{2}{*}{ Formula } & \multirow[b]{2}{*}{ MW } & \multirow[b]{2}{*}{ Sources } \\
\hline & $\mathrm{R}_{1}$ & $\mathrm{R}_{2}$ & $\mathrm{R}_{3}$ & $\mathrm{R}_{4}$ & $\mathrm{R}_{5}$ & $\mathrm{R}_{6}$ & & & \\
\hline $\mathrm{FA}_{1}$ & TCA & TCA & $\mathrm{OH}$ & $\mathrm{OH}$ & $\mathrm{NHCOCH}_{3}$ & $\mathrm{CH}_{3}$ & $\mathrm{C}_{36} \mathrm{H}_{61} \mathrm{NO}_{16}$ & 763 & \\
\hline $\mathrm{FA}_{2}$ & TCA & TCA & $\mathrm{H}$ & $\mathrm{OH}$ & $\mathrm{NHCOCH}_{3}$ & $\mathrm{CH}_{3}$ & $\mathrm{C}_{36} \mathrm{H}_{61} \mathrm{NO}_{15}$ & 747 & [14] \\
\hline $\mathrm{FA}_{3}$ & TCA & TCA & $\mathrm{OH}$ & $\mathrm{H}$ & $\mathrm{NHCOCH}_{3}$ & $\mathrm{CH}_{3}$ & $\mathrm{C}_{36} \mathrm{H}_{61} \mathrm{NO}_{15}$ & 747 & [14] \\
\hline $\mathrm{FAK}_{1}$ & $=\mathrm{O}$ & TCA & $\mathrm{OH}$ & $\mathrm{OH}$ & $\mathrm{NHCOCH}_{3}$ & $\mathrm{CH}_{3}$ & $\mathrm{C}_{30} \mathrm{H}_{53} \mathrm{NO}_{11}$ & 603 & {$[14]$} \\
\hline $\mathrm{FB}_{1}$ & TCA & TCA & $\mathrm{OH}$ & $\mathrm{OH}$ & $\mathrm{NH}_{2}$ & $\mathrm{CH}_{3}$ & $\mathrm{C}_{34} \mathrm{H}_{59} \mathrm{NO}_{15}$ & 721 & {$[14]$} \\
\hline $\mathrm{FB}_{2}$ & TCA & TCA & $\mathrm{H}$ & $\mathrm{OH}$ & $\mathrm{NH}_{2}$ & $\mathrm{CH}_{3}$ & $\mathrm{C}_{34} \mathrm{H}_{59} \mathrm{NO}_{14}$ & 705 & [14] \\
\hline $\mathrm{FB}_{3}$ & TCA & TCA & $\mathrm{OH}$ & $\mathrm{H}$ & $\mathrm{NH}_{2}$ & $\mathrm{CH}_{3}$ & $\mathrm{C}_{34} \mathrm{H}_{59} \mathrm{NO}_{14}$ & 705 & [14] \\
\hline $\mathrm{FC}_{1}$ & TCA & TCA & $\mathrm{OH}$ & $\mathrm{OH}$ & $\mathrm{NH}_{2}$ & $\mathrm{H}$ & $\mathrm{C}_{33} \mathrm{H}_{57} \mathrm{NO}_{15}$ & 707 & {$[14]$} \\
\hline $\mathrm{FP}_{1}$ & TCA & TCA & $\mathrm{OH}$ & $\mathrm{OH}$ & $3 \mathrm{HP}$ & $\mathrm{CH}_{3}$ & $\mathrm{C}_{39} \mathrm{H}_{62} \mathrm{NO}_{16}^{+}$ & 800 & {$[14]$} \\
\hline $\mathrm{FP}_{2}$ & TCA & TCA & $\mathrm{H}$ & $\mathrm{OH}$ & $3 \mathrm{HP}$ & $\mathrm{CH}_{3}$ & $\mathrm{C}_{39} \mathrm{H}_{62} \mathrm{NO}_{15}{ }^{+}$ & 784 & [14] \\
\hline $\mathrm{FP}_{3}$ & TCA & TCA & $\mathrm{OH}$ & $\mathrm{H}$ & $3 \mathrm{HP}$ & $\mathrm{CH}_{3}$ & $\mathrm{C}_{39} \mathrm{H}_{62} \mathrm{NO}_{15}{ }^{+}$ & 784 & {$[14]$} \\
\hline$* \mathrm{PH}_{1 \mathrm{a}}$ & TCA & $\mathrm{OH}$ & $\mathrm{OH}$ & $\mathrm{OH}$ & $\mathrm{NH}_{2}$ & $\mathrm{CH}_{3}$ & $\mathrm{C}_{28} \mathrm{H}_{53} \mathrm{NO}_{10}$ & 563 & {$[14]$} \\
\hline$* \mathrm{PH}_{1 \mathrm{~b}}$ & $\mathrm{OH}$ & TCA & $\mathrm{OH}$ & $\mathrm{OH}$ & $\mathrm{NH}_{2}$ & $\mathrm{CH}_{3}$ & $\mathrm{C}_{28} \mathrm{H}_{53} \mathrm{NO}_{10}$ & 563 & {$[14]$} \\
\hline$* \mathrm{NCMFB}_{1}$ & TCA & TCA & $\mathrm{OH}$ & $\mathrm{OH}$ & $\mathrm{NH}\left(\mathrm{C}_{2} \mathrm{H}_{3} \mathrm{O}_{2}\right)$ & $\mathrm{CH}_{3}$ & $\mathrm{C}_{36} \mathrm{H}_{61} \mathrm{NO}_{17}$ & 779 & [15] \\
\hline$* \mathrm{NDFB}_{1}$ & TCA & TCA & $\mathrm{OH}$ & $\mathrm{OH}$ & $\mathrm{NH}\left(\mathrm{C}_{6} \mathrm{H}_{11} \mathrm{O}_{5}\right)$ & $\mathrm{CH}_{3}$ & $\mathrm{C}_{40} \mathrm{H}_{69} \mathrm{NO}_{20}$ & 883 & {$[16]$} \\
\hline
\end{tabular}

*: Forms of fumonisin formed during processing 
Am. J. Infect. Dis., 5 (4): 273-281, 2009

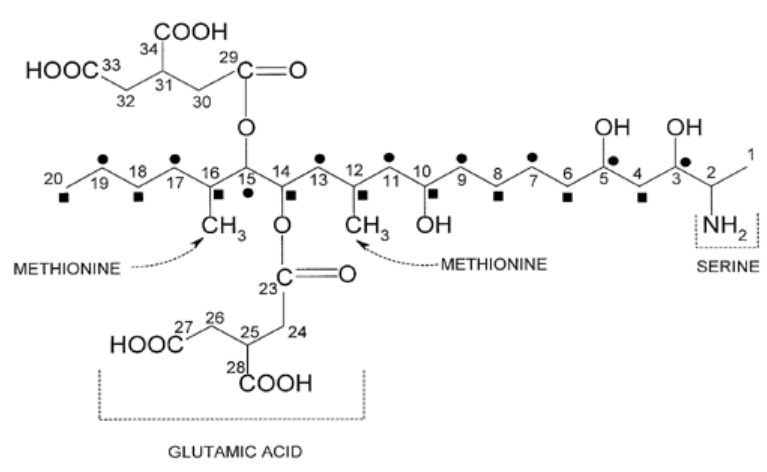

Fig. 2: Biosynthetic origins of FB1. Adapted from ${ }^{[12]}$

The A series of fumonisins, isolated from cultures of $F$. verticillioides and from whole corn, differs from the $\mathrm{B}$ series by the presence of a $\mathrm{N}$-acetyl amide group rather than an amine group at C-2 position ${ }^{[17]}$. The $\mathrm{C}$ series of fumonisins, which has been isolated from moldy corn, is chemically similar to B series, except that $\mathrm{C}-1$ terminal methyl group is missing in the $\mathrm{C}$ series off fumonisins ${ }^{[13]}$. Musser et al isolated and characterized a new series of fumonisins, designated the $\mathrm{P}$ series, from cultures of $F$. proliferatum grown on corn. These compounds contain a 3-hydroxypyridinium moiety at the C-2 position in the backbone instead of the amine found in the $\mathrm{B}$ series of fumonisins ${ }^{[19]}$.

Several fumonisin-related derivatives have been found in corn or are created as a result of chemical and/or thermal processing of food (Table 1 and Fig. 1). Heating purified fumonisins or naturally contaminated corn meal in the presence of alkali, in a process known as nixtamilization, results in partial and complete hydrolysis of the tricarballylic acid ester groups from the aminopolyol backbone (AP1 $)^{[11]}$. Two different fumonisin derivatives, N-(carboxymethyl) FB1 (NCMFB1) and N-(deoxy-D-fructos-1-yl) FB1 (NDFFB1), have been isolated from thermally treated solutions of FB1 and fructose or glucose, or in foods containing fumonisins and reducing sugars ${ }^{[15,16]}$.

Occurrence of fumonisins in foods and feeds: Fumonisin B1 and B2 has been reported in 'black oats' feed from Brazil ${ }^{[20]}$ and forage grass in New Zealand ${ }^{[21]}$. In forage grass, the occurrence of fumonisin was accompanied by mono- and dimethyl ester that may not have been $\operatorname{artifacts}^{[21]}$. In rural areas of Transkei, Southern Africa, FB1 and FB2 have been found in home-grown corn that produced and consumed by people whole living in there areas ${ }^{[10]}$.

Fumonisin have also been found in feeds that were associated with ELEM that obtained from South Africa, the United States and Brazil ${ }^{[18,20,22,23]}$. Wilson et al have reported that the level of FB1 and FB2 were as high as 122 and $23 \mu \mathrm{g} \mathrm{g}^{-1[23]}$. The concentration of FB1 that studied in the United States (US) suggest that it was greater than $10 \mu \mathrm{g} \mathrm{g}^{-1}$ in horse feed that could be involved with ELEM ${ }^{[18]}$. Most of the time, non-problem feeds contained below $6 \mu \mathrm{gFB} 1 \mathrm{~g}^{-1}$.

Fumonisin $\mathrm{B} 1$ also has been found in corn, corn screening and other feeds in the US and Brazil that cause Porcine Pulmonary Edema (PPE) ${ }^{[20,22]}$. These cases occurred because samples contained FB1 in excess of $10 \mu \mathrm{g} \mathrm{g}^{-1}$ with a maximum of $330 \mu \mathrm{g} \mathrm{g}^{-1[22]}$.

In several countries, commercial corn-based human foodstuffs from retail outlets contain fumonisin ${ }^{[24,25]}$. The fumonisin B1 and B2 that have been found in corn meal up to $2.98 \mu \mathrm{gFB} 1 \mathrm{~g}^{-1}$ and $0.92 \mu \mathrm{gFB} 2 \mathrm{~g}^{-1}$ and in corn grits up to $2.55 \mu \mathrm{gFB} 1 \mathrm{~g}^{-1}$ and $1.07 \mu \mathrm{gFB} 2 \mathrm{~g}^{-1}$ appear to be the biggest problems to corn meal and corn grits $^{[25]}$. The incidence and levels of FB1 $\left(<0.06 \mu \mathrm{g} \mathrm{g}^{-1}\right)$ that have been reported for cornflakes breakfast cereal in Switszerland, the United State and South Africa were very low ${ }^{[24,25]}$.

Prevention of plants contamination with fumonisins at the field level: Prevention methods that can be used to prevent the fumonisins contamination at the field level are crop rotation and tillage because crop rotation and tillage are recommended to control plant contamination with Fusarium sp. ${ }^{[26]}$. Besides these methods, fertilizers also can be used because it can alter the rate of residue decomposition, act on the rate of plant growth and change the soil structure and its microbial activity. These will affect Fusarium sp. contamination of crops. The symptoms of contamination observed when urea was used instead of ammonium nitrate are fewer ${ }^{[27]}$ because the incidence of Fusarium-infected grain increased when the nitrogen has been supplied to the grain ${ }^{[27]}$.

Mycotoxin risk can be reduced by enhancing the resistance to insect attack, induce the processes or detoxification pathway that inhibit the production of mycotoxin in the grain and increase the resistance of the plant to infection by using genetic engineering ${ }^{[28]}$. An enzyme from fungi and bacteria growing on stalk tissues and maize kernels which are able to degrade fumonisins have been isolated. Transgenic maize Bt maize that express Bt-toxin can be used to reduce fumonisin level in grains ${ }^{[29]}$.

Biological control can also be used to control the infection and struggle against toxigenic Fusarium $\mathrm{sp}^{[30]}$. The growth of toxin producer can be eradicated or limited by spraying microbial antagonist or competitors on plants at the flowering stage ${ }^{[31]}$ such as Bacillus subtilis which can inhibit fungi growth during 
endophytic growth phase ${ }^{[32]}$. Fumonisin production can be predicted by framework that produce from Fusarium proliferatum and Fusarium verticillioides in the field and provide early warning for an unacceptable risk of mycotoxin level ${ }^{[33]}$.

Harvest and post-harvest control of fumonisins: Physiological stage of plants: Due to the earlier maize ear development, the risk of fumonisin contamination may begin and increase throughout the physiological maturation of the infested maize ear. The level of fumonisin B1 that on dent stage kernel maize was highest while on the blister stage kernels, the level of fumonisin B1 was lowest ${ }^{[34]}$. Production of Fumonisin B1 in maize kernels by Fusarium moniliforme can continue after harvest prior to drying during the prestorage period of harvested and moist grains ${ }^{[35]}$.

Humidity level before and during storage: Atmospheric humidity in the morning dew and the sunny afternoon can vary greatly and it influences the water content of grains. Therefore the best time for harvesting is during the day because it is another essential factor for the evolution of Fusarium sp. in grains on the post-harvest period.

The effect of two moisture contents, 110 and $140 \mathrm{~g} \mathrm{~kg}^{-1}$ on mycoflora and toxin contamination was monitored bimonthly in 36 maize samples during a 12 month storage period. All freshly harvested corn was found to contain fumonisin and the content of fumonisins did not change in the 12 month stored corn. So, the moisture content at the crop harvesting predrying stage was important for determining the ultimate fungal and fumonisin level in maize ${ }^{[36]}$.

Physical treatment of contaminated grains: Usually, the fumonisin levels in broken corn kernels are about 10 times more than intact corn kernels. Cleaning the external surface of grains and eliminating the physically damaged kernels can minimize or avoid spore containing material and reduce the infection of healthy grains by contaminated ones ${ }^{[37]}$. Fumonisins contamination decreased about $70-90 \%$ by association with hand picking and density segregation techniques $^{[38]}$ while screening and gravity sorting techniques reduced the Fumonisin B1 and Fumonisin B2 about $60 \%$ that were applied to maize grains being discharged from a storage silo .

Most of mycotoxin can be considered as heat stable. Fumonisin B1 content was followed the first order decomposition kinetecs as temperature increased has been reported by ${ }^{[39]}$ and the possible partial loss of fumonisins during industrial processes involved has been confirmed by carrying out several experiment on contaminated food ${ }^{[40]}$.

After heating the Fumonisin B1 and Fumonisin B2 at $190^{\circ} \mathrm{C}$ for $60 \mathrm{~min}$, the contamination of both fumonisins losses exceeded $70 \%$ in maize meal contaminated at the level of $2.5 \mathrm{mg} \mathrm{kg}^{-1}$ and when heated at $220^{\circ} \mathrm{C}$ for $25 \mathrm{~min}$, the losses reached $100 \%{ }^{[41]}$. It was reported that fumonisin contamination decreased $60 \%$ when maize meal muffins were baked at $220^{\circ} \mathrm{C}$ for $25 \mathrm{~min}$ but there was no effect on Fumonisin $\mathrm{B} 1$ content after baking at $204^{\circ} \mathrm{C}$ for $20 \mathrm{~min}^{[42]}$.

The fate of fumonisins has been studied throughout corn flakes processing including cooking, flaking and toasting maize contaminated by direct adding or culturing grits with Fusarium proliferatum, 35-53\% of Fumonisin B1 were lost from cultured and spiked grits at the end of the process. After the addition of glucose to the contaminated maize, Fumonisin B1 disappearance reached 86 and $89 \%{ }^{[43]}$.

Fumonisins that found mainly in the solid fraction made of germ, fiber and gluten were insoluble. The distribution of mycotoxins among milling fractions in commercially dry milled food products depends on the fungal penetration of the endosperm. So, the milling grain with surface contamination contains lower contamination level in flour and higher in germ, bran and fines ${ }^{[44]}$.

Biological treatments: Enzymes from a filamentous saprophytic fungus growing on maize that capable to degrade fumonisins have been isolated and the corresponding genes have been cloned and transferred in transgenic maize ${ }^{[28]}$. Mycotoxins could be degraded by an alternative strategy by promoting gut microbes. Firstly, the identification of these microbes is needed to be done and after that the ecology of these microbes should be studied to know the best conditions for growth in the gastrointestinal tract. For example, rumen protozoa play a significant role in degrading some mycotoxins $^{[45]}$.

The toxicological effects of fumonisins: Since the isolation and characterization of fumonisins in 1988, considerable efforts have been made to study the toxicological properties of purified FB1, the most abundant and toxic of the fumonisin homologues. FB1 is responsible for various toxicoses in domestic animals. Purified FB1 was first shown to cause Equine Leukoencephalomalacia (ELEM) when the toxin was administered intravenously ${ }^{[8]}$ or orally to horses which is characterized by the presence of liquefactive necrotic lesions in the matter of the cerebrum ${ }^{[46]}$ and Porcine Pulmonary Edema (PPE) which is characterized by 
dyspnoea, weakness, cyanosis and death and hydrothorax in pigs ${ }^{[9]}$. Daily intake of fumonisin that induced PPE is $4.5-6.3 \mathrm{mg}$ fumonisin $\mathrm{kg}^{-1}$ bw day ${ }^{-1}$ and the "No Observed Adverse Effect Level" (NOAEL) is thus lower than $4.5 \mathrm{mg}$ fumonisin $\mathrm{kg}^{-1}$ bw day ${ }^{-1[47]}$ while the minimum dose that can cause ELEM in horses are between 0.2-0.44 mg fumonisin $\mathrm{kg}^{-1}$ bw day ${ }^{-1}$ and the NOAEL for horses is estimated at $0.2 \mathrm{mg}$ fumonisin $\mathrm{kg}^{-1}$ bw day ${ }^{-1[8]}$.

There are several studies with fumonisin performed in rodents for the sub-acute oral toxicity ${ }^{[1,48]}$. The fumonisin was found to be a rodent carcinogen that caused hepatic tumors in female mice ${ }^{[49]}$ and rats ${ }^{[50]}$ and induced renal tubule tumors in male rats ${ }^{[49]}$. There are also several studies of sub-acute toxicity that performed with other animal species such as poultry, rabbits, hamsters, non-human primates, lambs, mink and cattle. One of these studies, feeding of FB1 to broiler chicks caused reduced weight gains, mortality and lesions in several organs including the liver, kidney, heart and lung $^{[51]}$. The liver and kidney are the main target organs for FB1 in almost all animal species especially in mouse and rat because they are the most sensitive organs that might even depend on the strain or gender ${ }^{[52]}$.

The toxicity of several forms of fumonisin (FB1, FB2, FB3, FP1, AP1, FA1 and NCMFB1) was compared in a 28-day feeding study with female mice ${ }^{[53]}$. FB1 was the only fumonisin derivative to have hepatotoxic effects in this study. The primary amine group, found in the $\mathrm{B}$ and $\mathrm{C}$ series of fumonisins is necessary for the fumonisin to elicit toxicity ${ }^{[54]}$.

FB1 has been implicated to be associated with high rates of human esophageal cancer in South Africa where high intake of maize was contaminated with fumonisins ${ }^{[10]}$, the United States and China ${ }^{[55]}$ where natural occurrence of fumonisins in corn grown in these regions ${ }^{[56]}$. Exposure to fumonisin or $F$. verticillioidescontaminated corn has also been implicated as a possible risk factor for neural tube defects in South Africa, China and in the Southwestern USA ${ }^{[57]}$.

Most of the toxicities resulting from exposure to fumonisins can be explained by the ability of the toxin to alter sphingolipid metabolism by inhibiting the enzyme synthase, an enzyme responsible for the acylation of spingosine and sphinganine and palmitate or another fatty acid. The consequences of ceramide synthase inhibition are increase in cellular sphinganine and to a lesser degree, sphingosine concentrations, elevated sphingoid base breakdown products such as sphinosine-1-phosphate and decrease in cellular complex sphingolipids (Fig. 3). Since fumonisins disrupt sphingolipid biosynthesis, the resulting elevation in the sphinganine/sphingosine ratio in serum, plasma, or urine has been used as a biomarker for estimating dietary exposure to fumonisin in animals ${ }^{[56]}$.

Economic impact of fumonisins: The economic impact of mycotoxins on humans and animal agriculture can be assessed by multiple criteria such as the loss of human and animal life, health and veterinary care costs, loss of livestock production, forage crops and feeds, regulatory costs and research cost focusing on relieving the impact and severity of the mycotoxin problem ${ }^{[59]}$.

The total field maize production in 2005 was estimated at 10.6 billion bushels, or 3.73 hectoliters and the price of maize for the animal feed was US\$ 1.73 per bushel, or US\$ 0.61 per hectoliter. Regulations for fumonisins in animal feed currently exist elsewhere worldwide were very few. Therefore, from now the trade-related losses will focus on domestic market losses ${ }^{[60]}$.

The estimation of economic value of horse deaths causes by ELEM due to fumonisin contaminated feeds required information on horse market prices as well as number of annual deaths that both have a fair amount of variability and uncertainty. For example, the average price of horses sold in 1998 in US was US\$ 3150 with a range from US\$ 1000 for horses sold in Montana to US\$ 10,000 for horses sold in Maryland. However, show horses can be sold at very expensive rates in the range from thousands to tens of thousands dollars but racehorses can be sold in the range thousands to millions of dollars ${ }^{[60]}$.

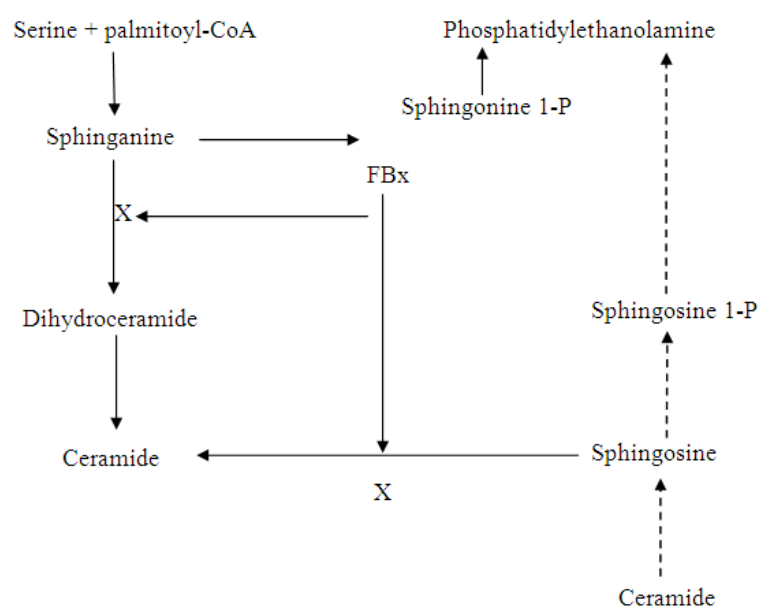

Fig. 3: Fumonisin (FBx) inhibit ceramide synthase which catalyzes the formation of ceramide ${ }^{[58]}$ 
The losses in a Fusarium ear rot outbreak could be far more severe. At least 55 documented ELEM cases in horses resulted in the 1989 outbreak $^{[22]}$, in which about $75 \%$ of their feed samples was found contaminated with $10 \mathrm{mg}$ fumonisin $\mathrm{kg}^{-1}$ (ranging from 1-126 mg kg${ }^{-1}$ ). The exact number of horse deaths was probably much higher. There were at least 42 documented cases of PPE in pigs in that same year and $71 \%$ of the cases involved feed contaminated with $10 \mathrm{mg}$ fumonisin $\mathrm{kg}^{-1[22]}$. In Kentucky and Virginia alone, there were at least 38 horses deaths resulted in the 1995 outbreak when the maize used for their feed was contaminated with fumonisin at $15 \mathrm{mg} \mathrm{kg}^{-1}$.

Fusarium ear rot outbreak in Indiana in 1991 was $43 \%$ of ears sustained damage in over $3 \%$ of their kernels. About 101 samples from 113 samples tested were detected contaminated with fumonisin and 50 of these samples had concentration of fumonisin greater than $50 \mathrm{mg} \mathrm{kg}^{-1}$ and this will certainly cause adverse health effects in horses, pigs and variety of other animal species if consumed. Assuming that $15-25 \%$ of maize from the case above, the expected marketplace losses would range from US\$ 27.5-45.8 million in maize rejected domestically for excessive contamination. The horse mortality loss would be about US $\$ 315,000$ if the 100 horse deaths arise nationwide from fumonisininduced ELEM in outbreak year ${ }^{[60]}$.

The average price of pigs that sold wholesale in the market in the US was US\$ 44.40 per hundredweight (cwt; $112 \mathrm{lb}$ ) in US\$ 2005 while the average price of hogs that sold in the US was $£ 108$ and a Standard Deviation (SD) of $30(49 \mathrm{~kg}$, SD $14 \mathrm{~kg})$. The pig mortality loss would be about US\$ 5000 if there were at least 100 pig deaths due to PPE in outbreak a year. Thus this will pose an additional economic loss to livestock farmers ${ }^{[60]}$.

\section{CONCLUSION}

Since their discovery in 1988, fumonisins have been the subject of numerous toxicological investigations. Fumonisins are natural contaminants of cereal grains worldwide and are mostly found in corn and corn-based products. The high levels of fumonisins that occur in foods and feeds, along with the ability of FB1 that causes certain diseases in farm animals such as ELEM, PPE and liver cancer in rats resulted in serious problems in both health and economy. Fumonisin has also been reported to cause esophageal cancer in human in some countries such as China, the United States and South Africa. There are various strategies that being pursued to develop methods to reduce fumonisins in corn or in corn-based animal feed products during both pre- and post-harvest periods in attempt to minimize the risk of feed contamination such as physical and biological processes but the effectiveness and commercial feasibility of these methods remain to be demonstrated. The current technology and studies pursued for the detection of fumonisin and prevention of fumonisin-related diseases need further development and refining. The awareness of the animal diseases associated with fumonisin exposure combined with reducing exposures through feed monitoring and adherence to appropriate USFDA or European Union guidances is important to minimize fumonisin-related diseases and production problems in animals.

\section{REFERENCES}

1. Gelderblom, W.C.A., K. Jaskiewicz, W.F.O. Marasas, P.G. Thiel, R.M. Horak, R. Vleggar and N.P. Kriek, 1988. Fumonisins-novel mycotoxins with cancerpromoting activity produced by Fusarium moniliforme. Applied Environ. Microbiol., 54: 1806-1811. http://aem.asm.org/cgi/content/abstract/54/7/1806

2. Weidenbörner, M., 2001. Foods and fumonisins. Eur. Food Res. Technol., 212: 262-273. DOI: 10.1007/s002170000259

3. Da Silva, J.B., C.R. Pozzi, M.A.B. Mallozzi, E.M. Ortega and B. Corrêa, 2000. Mycoflora and occurence of aflatoxin B1 and fumonisin B1 during storage of Brazilian sorghum. J. Agric. Food Chem., 48: 4352-4356. DOI: 10.1021/jf990054w

4. Tseng, T.C. and J.C. Tu, 1997. Mycoflora and mycotoxins in adzuki and mung beans produced in Ontario, Canada. Microbios, 90: 87-95. http://www.ncbi.nlm.nih.gov/entrez/query.fcgi?cmd=Ret rieve $\& \mathrm{db}=$ PubMed $\&$ dopt $=$ Citation\&list_uids $=9345788$

5. Martins, M.L., H.M. Martins and F. Bernando, 2001. Fumonisin B1 and B2 in black tea and medicinal plants. J. Food Protect., 64: 1268-1270. http://www.ncbi.nlm.nih.gov/entrez/query.fcgi?cm $\mathrm{d}=$ Retrieve $\& \mathrm{db}=$ PubMed\&dopt=Citation\&list_uids $=11510675$

6. Chelkowski, J., 1998 Distribution of Fusarium Species and Their Mycotoxins in Cereal Grains. In: Mycotoxins in Agriculture and Food Safety, Sinhaand, K.K. and D. Bhatnagar (Eds.). CRC Press, Marcel Dekker, New York, ISBN: 9780824701925, pp: 520.

7. Julian, A.M., P.W. Wareing, S.I. Phillips, V.F.P. Medlock, M.V. Macdonald and L.E. Del Rio, 1995. Fungal contamination and selected mycotoxins in pre-and post-harvest maize in Honduras. Mycopathologia, 129: 5-16. DOI: 10.1007/BF01139331 
8. Marasas, W.F.O., T.S. Kellerman, W.C.A. Gelderblom, J.A.W. Coetzer, P.G. Thiel and J.J. Van Der Lugt, 1988. Leukoencephalomalacia in a horse induced by fumonisin B1 isolated from Fusarium moniliforme. Onderstepoort J. Vet. Res., 55: 197-203. http://www.ncbi.nlm.nih.gov/entrez/query.fcgi?cm $\mathrm{d}=$ Retrieve $\& \mathrm{db}=$ PubMed\&dopt=Citation\&list_uids $=3217091$

9. Haschek, W.M., G. Motelin, D.K. Ness, K.S. Harlin, W.F. Hall, R.F. Vesonder, R.E. Peterson and V.R. Beasley, 1992. Characterization of fumonisin toxicity in orally and intravenously dosed swine. Mycopathologia, 117: 83-96. DOI: 10.1007/BF00497283

10. Rheeder, J.P., W.F.O. Marasas, P.G. Thiel, E.W. Syndenham, G.S. Shephard and D.J. Van Schalkwyk, 1992. Fusarium moniliforme and fumonisins in corn in relation to human esophageal cancer in Transkein. Phytopathology, 83: 353-357. DOI: 10.1094/Phyto-82-353

11. Scott, P.M., 1993. Fumonisin. Int. J. Food Microbiol., 18: 257-270. DOI: 10.1016/01681605(93)90149-B

12. Blackwell, B.A., O.E. Edwards, J.W. Apsimon and A. Fruchier, 1995. Relative configuration of the C10 to C-16 fragment of fumonisin B1. Tetrahedron Lett., 36: 1973-1976. DOI: 10.1016/00404039(95)00205-Q

13. Seo, J.A. and Y.W. Lee, 1999. Natural occurrence of the $\mathrm{C}$ series of fumonisins in moldy corn. Appl. Environ. Microbiol., 65: 1331-1334. http://aem.asm.org/cgi/content/full/65/3/1331

14. Musser, S.M. and R.D. Plattner, 1997. Fumonisin composition in cultures of Fusarium moniliforme, Fusarium proliferatum and Fusarium nygami. J. Agric. Food Chem., 45: 1169-1173. DOI: 10.1021/jf960663t

15. Howard, P.C., M.I. Churchwell, L.H. Couch, M.M. Marques and D.R. Doerge, 1998. Formation of $\mathrm{N}$-(carboxymethyl)fumonisin $\mathrm{B} 1$, following the reaction of fumonisin B1 with reducing sugars,. J. Agric. Food Chem., 46: 3546-3557. DOI: 10.1021/jf980194q

16. Poling, S.M., R.D. Plattner and D.N. Weisleder, 2002. N-(1-Deoxy-D-fructos-1-yl) fumonisin B1 the initial reaction product of fumonisin B1 and Dglucose. J. Agric. Food Chem., 50: 1318-1324. DOI: $10.1021 / \mathrm{jf010955g}$

17. Cawood, M.E., W.C.A. Gelderblom, R. Vleggaar, Y. Beh, P.G. Thiel and W.F.O. Marasas, 1991. Isolation of the fumonisin mycotoxins: A quantitative approach. J. Agric. Food Chem., 39: 1958-1962. DOI: 10.1021/jf00011a014
18. Ross, P.F., L.G. Rice, G.D. Osweiler, P.E. Nelson, J.L. Richard and T.M. Wilson, 1992. A review and update of animal toxicoses associated with fumonisin-contaminated feeds and production of fumonisins by Fusarium isolates. Mycopathologia, 117: 109-114. DOI: 10.1007/BF00497286

19. Musser, S.M., M.L. Gay and E.P. Mazzola, 1996. Identification of a new series of fumonisins containing 3-hydroxypyridine. J. Nat. Prod., 59: 970-972. DOI: 10.1021/np960349t

20. Sydenham, E.W., W.F.O. Marasas, G.S. Shephard, P.G. Thiel and E.Y. Hirooka, 1992. Fumonisin concentrations in Brazilian feeds associated with field outbreaks of confirmed and suspected animal mycotoxicoses. J. Agric. Food Chem. 40: 994-997. DOI: 10.1021/jf00018a016

21. Mirocha, C.J., C.G. Mackintosh, U.A. Mirza, W. Xie, Y. Xu and J. Chen, 1992. Occurrence of fumonisin in forage grass in New Zealand. Applied Environ. Microbiol., 58: 3196-3198. http://www.pubmedcentral.nih.gov/articlerender.fc gi?tool=pubmed $\&$ pubmedid $=16348778$

22. Ross, P.F., L.G. Rice, R.D. Plattner, T.M. Wilson and D.L. Owens, 1991. Concentrations of fumonisin B1 in feeds associated with animal health problems. Mycopathologia, 114: 129-135. DOI: $10.1007 / \mathrm{BF} 00437200$

23. Wilson, T.M., Ross. P.F., L.G. Rice, G.D. Osweiler and H.A. Nelson et al., 1990. Fumonisin B1 levels associated with an epizootic of equine leukoencephalomalacia. J. Vet. Diagn. Invest., 2: 213-216. http://jvdi.org/cgi/reprint/2/3/213

24. Pittet, A., V. Parisod and M. Schellenberg, 1992. Occurrence of fumonisins B I and B 2 in cornbased products from the Swiss market. J. Agric. Food Chem., 40: 1352-1354. DOI: 10.1021/jf00020a012

25. Sydenham, E.W., G.S. Shephard, P.G. Thiel, W.F.O. Marasas and S. Stockenström, 1991. Fumonisin contamination of commercial cornbased human foodstuffs. J. Agric. Food Chem., 39: 2014-2018. DOI: 10.1021/jf00011a028

26. Sutton, J.C., 1982. Epidemiology of wheat head blight and maize ear rot caused by Fusarium graminearum. Can. J. Plant Pathol., 4: 195-209. http://www.cps-scp.ca/download/cjpparchive/Vol4/CJPP4(2)195-209(1982).pdf

27. Martin, R.A., J.A. Macleod and C. Caldwell, 1991. Influences of production imputs on incidence of infection by Fusarium species on cereal seed. Plant Dis., 75: 784-788. DOI: 10.1094/PD-75-0784 
28. Duvik, J., 2001. Prospects for reducing fumonisin contamination of maize through genetic modification. Environ. Health Perspect., 109: 337-342. http://www.pubmedcentral.nih.gov/articlerender.fc gi?artid=1240685

29. Hammond, B.G., K.W. Campbell, C.D. Pilcher, T.A. Degoover and A.E. Robinson, 2004. Lower fumonisin mycotoxin levels in the grain of $\mathrm{Bt}$ corn grown in the United states in 2000-2002. J. Agric. Food Chem., 52: 1390-1397. DOI: 10.1021/jf030441c

30. Dawson, W.A.J.M., G.L. Baterman, J. Köhl, B.H. De Haas and C.H. Lombaers-Van Der Plas, "Controlling infection of cereal grain by toxigenic Fusarium species using fungal competitors. Proceeding of the BCPC Conference on Pests and Diseases, British Crop Protection Council, Nov. 2002, pp. 347-352.

http://www.cababstractsplus.org/abstracts/Abstract. aspx?AcNo=20033026821

31. Schisler, D.A., N.I. Khan, M.J. Boehm and P.J. Slininger, 2002. Greenhouse and field evaluation of biological control of Fusarium head blight on durum wheat. Plant Dis., 86: 1350-1356. DOI: 10.1094/PDIS.2002.86.12.1350

32. Bacon, C.W., I.E. Yates, D.M. Hinton and M. Filmore, 2001. Biological control of Fusarium moniliforme in maize. Environ. Health Perspect., 109: 325-343. http://www.pubmedcentral.nih.gov/articlerender.fc gi?artid=1240683

33. Marin, S., N. Magan, N. Belli, A.J. Ramos, R. Canela and V. Sanchis, 1999. Two-dimensional profile of fumonisin B1 production by Fusarium moniliforme and Fusarium proliferatum in relation to environmental factors and potential for modelling toxin formation in maize grain. Int. J. Food Microbiol., 51: 159-167.

http://www.ncbi.nlm.nih.gov/entrez/query.fcgi?cmd=Ret rieve $\& \mathrm{db}=$ PubMed $\& d o p t=$ Citation\&list_uids $=10574091$

34. Warfield, C.Y. and D.G. Gilchrist, 1999. Influence of kernel age on fumonisin B1 production in maize by Fusarium moniliforme. Applied Environ. Microbiol., 65: 2853-2856. http://aem.asm.org/cgi/content/full/65/7/2853

35. Cahagnier, B., D. Melcion and D. Richard-Molard, 1995. Growth of Fusarium moniliforme and its biosynthesis of fumonisin B1 on maize grain as a function of different water activities. Lett. Applied Microbiol., 20: 247-251. DOI: 10.1111/j.1472765X.1995.tb00439

36. Ono, E.Y., E.Y. Sasaki, E.H. Hashimoto, L.N. Hara, and B. Correa, 2002. Post-harvest storage of corn: Effect of beginning moisture content on mycoflora and fumonisin contamination. Food Addit. Contam., 19: 1081-1090. DOI: $10.1080 / 02652030210146828$
37. Balzer, A., D. Tardieu, J.D. Bailly and P. Guerre, 2004. The trichothecenes: Toxins nature, natural occurrence in food and feeds and ways of struggle.

Rev. Med. Vet., 155: 299-314. http://www.scopus.com/scopus/record/display.ur 1 ? view $=$ basic $\&$ eid $=2-\mathrm{s} 2.0$ $4344586211 \&$ origin $=$ resultslist $\&$ sort $=$ plf-f $\&$ cite $=2-$ s 2.0 $4344586211 \&$ src $=$ s\&imp $=$ t\&sid $=$ GTVGvNDRBRixlxY UgOkkOnA\%3a110\&sot=cite\&sdt=a\&sl=0

38. Vasanthi, S. and R.V. Bath, 1998. Mycotoxins in foods: Occurrence, health and economic significance and food control measures. Indian J. Med. Res., 108: 212-224. http://www.ncbi.nlm.nih.gov/entrez/query.fcgi?cm $\mathrm{d}=$ Retrieve $\& \mathrm{db}=$ PubMed\&dopt $=$ Citation\&list_uids $=9863277$

39. Dupuy, J., P. Le Bars and H. Boudra, 1993. Thermostability of fumonisin B1, a mycotoxin from Fusarium moniliforme in corn. Applied Environ. Microbiol., 59: 2864-2867. http://aem.asm.org/cgi/content/abstract/59/9/2864

40. Park, J.W., P.M. Scott, B.P.Y. Lau and D.A. Lewis, 2004. Analysis of heat-processed corn foods for fumonisins and bound fumonisins,. Food Addit. Contam., 21: 1168-1178. DOI: $10.1080 / 02652030400021873$

41. Scott, P.M. and G.A. Lawrence, 1994. Stability and problems in recovery of fumonisins added to cornbased foods. J. AOAC. Int., 77: 541-545. http://www.ncbi.nlm.nih.gov/entrez/query.fcgi?cmd=Ret rieve $\& d b=$ PubMed\&dopt $=$ Citation\&list_uids $=8199487$

42. Castelo, M.M., S.S. Summer and L.B. Bullerman, 1998. Stability of fumonisins in thermally processed corn products. J. Food Prot., 61: 1030-1033. http://www.ncbi.nlm.nih.gov/entrez/query.fcgi?cm $\mathrm{d}=$ Retrieve $\& \mathrm{db}=$ PubMed\&dopt=Citation\&list_uids $=9713766$

43. Castelo, M.M. and L.B. Bullerman,2001. Reduction of fumonisin by the corn flake process. Proceeding of the AACC Annual Meeting, Oct. 1418, AACC Press. http://www.aaccnet.org/meetings/2001/Abstracts/a 01ma362.htm

44. Saunders, D.S., F.I. Meredith and K.A. Voss, 2001. Control of fumonisin: Effect of processing. Environ. Health Perspect., 109: 333-336. http://www.ehponline.org/members/2001/suppl2/333-336saunders/saunders-full.html

45. Westlake, K., R.I. Mackie and M.F. Dutton, 1989. In vitro metabolism of mycotoxins by bacterial, protozoal and ovine ruminal fluid preparations. Anim. Feed Sci. Technol., 25: 169-178. DOI: 10.1016/0377-8401(89)90117-X 
46. Wilson, T.M., Ross. P.F., D.L. Owens, L.G. Rice, S.A. Green, S.J. Jenkins and H.A. Nelson, 1992. Experimental reproduction of ELEM Mycophatologia, 117: 115-120. DOI: 10.1007/BF00497287

47. Motelin, G.K., W.M. Haschek, D.K. Ness and W.F. Hall, 1994. Temporal and dose-response features in swine fed corn screenings contaminated with fumonisin mycotoxins. Mycopathologia, 126: 27-40. DOI: 10.1007/BF01371170

48. Suzuki, C.A.M., L. Hierlihy, M. Barker, I. Curran, R. Mueller and G.S. Bondy, 1995. The effects of fumonisins on several markers of nephrotoxicity in rats. Toxicol. Applied Pharmacol., 133: 207-214. DOI: 10.1006/taap.1995.1143

49. Howard, P.C., R.M. Eppley, M.E. Stack and A. Warbritton, 2001. Fumonisin B1 carcinogenicity in a two-year feeding study using F344 rats and B63C3F1 mice. Environ. Health Perspect., 109: 277-282. http://www.ehponline.org/members/2001/suppl2/277-282howard/howard-full.html

50. Gelderblom, W.C.A., N.P. Kriek, W.F.O. Marasas and P.G. Thiel, 1991. Toxicity and carcinogenicity of the Fusarium monilffbrme metabolite, fumonisin B I, in rats. Carcinogenesis, 12: 1247-1251. http://www.ncbi.nlm.nih.gov/entrez/query.fcgi?cm $\mathrm{d}=$ Retrieve $\& \mathrm{db}=$ PubMed\&dopt=Citation\&list_uids $=1649015$

51. Javed, T., G.A. Bennett, J.L. Richard, M.A. Dombrink-Kurtzman, L.M. Cote and W.A. Buck, 1993. Mortality in broiler chicks on feed amended with Fusarium proliferatum culture material or with purified fumonisin B1 and moniliformin. Mycopathologia, 123: 171-84. http://www.ncbi.nlm.nih.gov/entrez/query.fcgi?cm $\mathrm{d}=$ Retrieve $\& \mathrm{db}=$ PubMed\&dopt=Citation\&list_uids $=8302366$

52. Carlson, D.B., D.E. Williams, J.M. Spitsbergen and P.F. Ross, 2001. Fumonisin B1 promotes aflatoxin $\mathrm{B} 1$ and $\mathrm{N}$-methyl-N'-nitrosoguanidine-initiated liver tumors in rainbow trout. Toxicol. Appl. Pharmacol., 172: 29-36. DOI: 10.1006/taap.2001.9129
53. Howard, P.C., L.H. Couch, R.E. Patton, R.M. Eppley and D.R. Doerge, 2002. Comparison of the toxicity of several fumonisin derivatives in a 28-day feeding study with female $\mathrm{B} 6 \mathrm{C} 3 \mathrm{~F}(1)$ mice. Toxicol. Applied Pharmacol., 185: 153-165. DOI: 10.1006/taap.2002.9529

54. Lemke, S., S.E. Ottinger, C.L. Ake, K. Mayura and T.D. Phillips, 2001. Deamination of the fumonisin B1 and biological assessment of reaction product toxicity. Chem. Res. Toxicol., 14: 11-15. DOI: 10.1021/tx000166d

55. Yoshizawa, T., A. Yamashita and Y. Luo, 1994. Fumonisin occurrence in corn from high- and lowrisk areas for human esophageal cancer in China Applied Environ. Microbiol., 60: 1626-1629. http://aem.asm.org/cgi/reprint/60/5/1626

56. Marasas, W.F.O., 2001. Discovery and occurrence of the fumonisin: A historical perspective. Environ. Health Perspect., 109: 239-243. http://www.ehponline.org/members/2001/suppl2/239-243marasas/marasas-full.html

57. Hendricks, K., 1999. Fumonisins and neural tube defects in South Texas. Epidemiol., 10: 198-200. http://www.ncbi.nlm.nih.gov/entrez/query.fcgi?cm $\mathrm{d}=$ Retrieve $\& \mathrm{db}=$ PubMed\&dopt $=$ Citation\&list_uids $=10069261$

58. Voss, K.A., P.C. Howard, R.T. Riley, R.P. Sharma, T.J. Bucci and R.J. Lorentzen, 2002. Carcinogenicity and mechanism of action of fumonisin B1: A mycotoxin produced by Fusarium moniliforme. Cancer Detect. Prevent., 26: 1-9. DOI: 10.1016/S0361-090X(02)00011-9

59. Hussein, H.S. and M.B. Jeffrey, 2001. Toxicity, metabolism and impact of mycotoxins on humans and animals. Toxicology, 167: 101-134. DOI: 10.1016/S0300-483X(01)00471-1

60. Wu, F., 2007. Measuring the economic impacts of Fusarium toxins in animal feeds J. Anim. Feed Sci. Tech., 137: 363-374. DOI: 10.1016/j.anifeedsci.2007.06.010 